\title{
Innovación en la docencia en el rotatorio de los alumnos de Medicina en la asignatura de Urología
}

\author{
María Fernanda Lorenzo Gómez
}

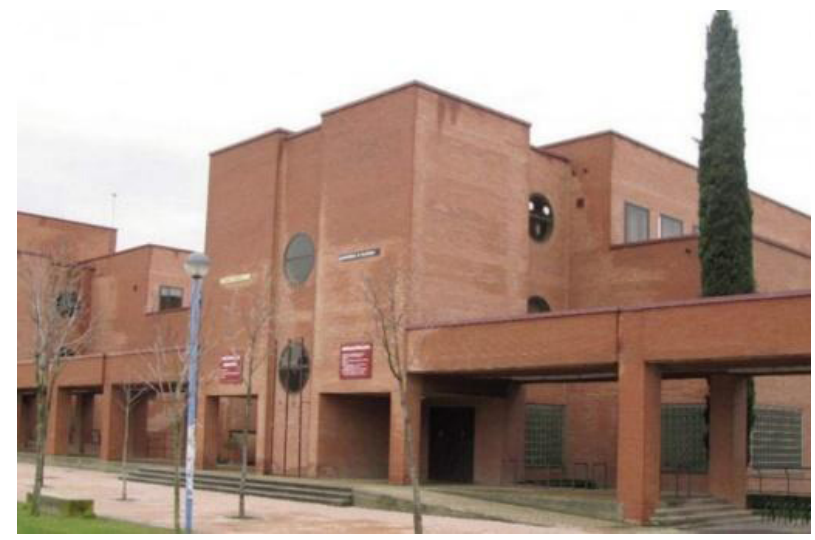

\footnotetext{
ON El OBJETIVO DE CONSEGUiR un mejor aprovechamiento de las prácticas clínicas de los alumnos de Medicina y en línea con las opiniones y sugerencias de mejora expresadas por los estudiantes, se plantea una nueva forma de organizar el rotatorio de los alumnos de Medicina en la asignatura de Urología.

Los/las estudiantes de Medicina son asignados por grupos de 3 a 6 personas a las «prácticas en Urología» en las distintas asignaturas de Rotatorio (desde cuarto curso hasta sexto).

Son recibidos por la coordinadora de la docencia, que les explica la composición y el funcionamiento del Servicio, así como de las prácticas. Este funcionamiento de las prácticas consiste en:

- Distribuir al alumnado entre los profesores asociados en orden alfabético.

- Rotar semanalmente con cada profesor/a durante las tres semanas de duración de las prácticas.

- Se presenta a los/las estudiantes la plantilla de evaluación de las prácticas para que se orienten en lo que se les va a evaluar.
} 
El elemento fundamental de esta práctica consiste en elaborar una memoria diaria que los/las estudiantes remitirán a la coordinadora de la docencia en la asignatura en la que deben incluir:

- Profesor adjudicado.

- Profesor efectivo.

- Actividad asistida/observada: consulta, quirófano, pruebas complementarias, planta, urgencias e interconsultas.

- Contenidos aprendidos.

- Datos claves.

- Dudas.

Las memorias electrónicas son revisadas a diario; corrigiendo los errores de interpretación, respondiendo a las dudas y concre-

Los estudiantes elaboran memorias electrónicas diarias y están implicados en la asignatura y atendidos, en contacto libre y directo con el profesor.

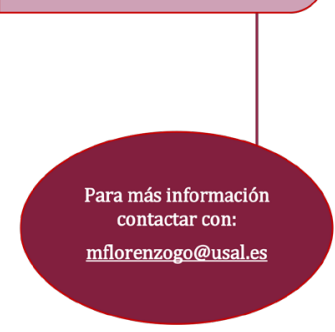
tando actividades para los días subsiguientes.

Esta forma de desarrollar el Rotatorio anima al alumnado a realizar trabajos de Urología en los que reflejan lo experimentado y aprendido. En ocasiones esto les lleva incluso a realizar trabajos de revisión bibliográfica del estado de la cuestión.

Las memorias que estos estudiantes elaboran constituyen herramientas valiosas para los cursos siguientes en los que reciben la correspondiente docencia teórica.

Las innovaciones son:

- El alumnado dispone de información precisa y concreta del responsable de la Rotación y de los elementos de la evaluación.

- La perspectiva del estudiante y su aprovechamiento de las prácticas cambia con la obligación de elaborar diariamente una memoria de su aprendizaje.

- Esta forma de desarrollar las prácticas permite llevar un registro de las mismas (incluyendo encuestas anónimas a los/las estudiantes) que posibilita un análisis por terceros de las memorias realizadas.

- Se prevé hacer una publicación en la revista oficial de divulgación científica de la Confederación Americana de Urología y en la Asociación Española de Urología. 